\title{
Extreme-Right Communication in Italy and France: Political Culture and Media Practices in CasaPound Italia and Les Identitaires
}

\begin{abstract}
Although the media are ascribed much power in discussions about far-right politics, to date the communicative dimension of extreme right mobilization received little rigorous scholarly attention. To address this gap, this paper addresses the media practices of the extreme right, offering an empirical study of two emerging social movement organizations of this area: CasaPound Italia in Italy and Les Identitaires in France. Rather than treating them as incidental beneficiaries of media populism, the paper disentangles the various ways in which these groups interact with the mass media, discussing the forms and meaning of their activism in relation to extreme right political culture, and differentiating between inward-oriented and outward-oriented media practices. Based on ethnographic observation and semi-structured interviews with far-right militants, the paper shows that media practices not only try to respond to the demands of the media environment in which the groups are embedded, but also seek to reinforce the groups' internal organization and hierarchy, building collective symbolic imagery, and ensuring ideological consistency among activists and sympathizers. In so doing, the paper offers initial insight on how protest movements of the extreme right consolidate their profile and become recognizable in the public sphere.
\end{abstract}

Keywords: Extreme right, media practices, social movements, Italy, France. 


\section{Introduction}

The relationship between extreme right-wing organizations and the media is far from straightforward. On the one hand, the far right ${ }^{1}$ is traditionally suspicious of the media system, which is blamed for promoting liberal values and sustaining the status quo (Mudde, 2007). On the other, media attention allows dissemination of far right messages beyond a group's limited constituency, especially in its early stages of development (Ellinas, 2010). Online media have come to represent a crucial arena for recruitment and propaganda by right-wing groups (Caiani and Parenti, 2009; Caren and Gaby, 2012; Froio, 2017), which use their own alternative media networks, web services and platforms to create and exploit cultural divisions (Atkinson and Berg, 2016). However, these aspects have received little systematic attention in social scientific research, especially concerning the media activism of far-right actors themselves (Golder, 2016).

This paper seeks to redress this gap in three main ways. First, building upon extant scholarship at the intersection between social movement research and media studies, we follow a practice-oriented approach to understand the interaction between the media and broader social processes (Couldry, 2004; Kubitschko, 2017). Instead of replicating previous investigations of media content or media effects on far-right politics, we set out to understand the media-oriented practices of extreme right organizations. Second, in line with the remit of this Special Issue, we intend to review the cultural specificity of these media practices, and their reproduction in right-wing alternative media content and style. We shall thus elaborate on the interplay between various forms of media practice and rightwing societal views and beliefs concerning political change and strategic choice. Third, we move beyond the preoccupation with 'demand-side' or 'externalist' explanations that characterize most literature on the far right (Goodwin, 2006; Castelli Gattinara and Pirro, 2019), and offer an empirical investigation of two emergent extreme right groups in Italy and France, CasaPound Italia, and Les Identitaires, based on insider ethnographic information about their internal workings.

Concerning the first aspect, extant scholarship related to the far right appraises the media primarily in terms of political and discursive opportunities, focusing on news coverage and electoral campaigning (Akkerman, 2011; Sheets, Bos and Boomgaarden, 2015). This literature recognizes that the mass media offer crucial resources for actors holding a minority position in the institutional arena, or striving to influence mainstream values with non-electoral means. Lacking the means to access the public sphere, these actors must rely on the mass media to make their arguments heard by the public (Ellinas, 2010). Even though journalistic norms may at times limit the coverage of extreme right politics, the media can help right-wing actors gain visibility by providing attention to issues on which they enjoy enhanced public credibility, notably immigration and security (Boomgaarden and Vliegenthart, 2007). In this sense, the success of the far right is aligned to the populist campaigns led by tabloids and mainstream television, which seek sensationalist and personalized news to cope with commercial pressures (Mazzoleni, 2008). While useful to identify similarities between logics of newsgathering and the characteristics of right-wing parties (Arzheimer and Carter, 2006), this

\footnotetext{
${ }^{1}$ The article refers to 'far right' as an umbrella concept including extreme and radical organizations located at the right end of the ideological spectrum (e.g. Mudde, 2007). Within this broader category of actors, the two organizations under study are extreme right, in that their ideologies oppose democratic principles and ultimately aim at subverting the democratic order. This sets them apart from other radical right actors who are simply hostile to liberal democratic principles but subscribe to the rules of parliamentary democracy.
} 
literature neglected the study of what the far right does in relation to the media, i.e. the practices by which it interacts with media objects.

In this respect, the literature on media and protest action can help fill a gap in scholarly knowledge of far-right politics. This research has in fact increasingly turned to studying the use of media (including new technologies) for mobilization purposes, including the production, dissemination and management of social movements' own media (Mattoni, 2012; Castelli Gattinara and Froio, 2018). This implies a shift towards considering the media as a discursive and technological environment with which movement actors interact, and through which they articulate their political goals (McCaughey and Ayers, 2013). More specifically, previous studies have theorized media 'as practice' rather than as text or as 'structures of production' (Couldry, 2004, p. 129), referring to the social practices by which activists interact with media objects and media subjects, and through which they understand the media environment in which they operate (Mattoni, 2017; Kubitschko, 2017). By applying a media practice perspective to the study of far-right politics, we thus seek to investigate the wide range of practices that extreme right-wing organizations orient to the media, and the activities that these groups deploy in relation to the media across different situations and contexts.

The second main contribution of this study concerns understanding media practice in relation to extreme-right beliefs and values on strategy and organization. Hence, we appraise media practices as a heuristic tool to observe and explain empirically the broader communicative dimension of extremeright politics, most specifically in terms of political culture (Mattoni, 2017; Kavada, 2013). In line with the remits of this Special Issue, we conceptualize political culture in relation to social movements, and identify it with the system of meaning, beliefs and values that underlie a movement's activity. $^{2}$ This includes the way in which a group apprehends strategy and organization, as well as its practices of meaning construction: how they make sense of their action, and how they interpret grievances as political (see, e.g. Ullrich, Daphi and Baumgarten, 2014). Social movements' political culture thus refers not only to a movement's general understanding of social and political change, but also to the way it understands its own role (and that of other actors, institutions, political opponents and allies) in producing societal change (see: Pirro and Castelli Gattinara, 2018). Thus, this paper looks at the cultural input embedded in political practices, recognizing that most strategic engagements involve deep cultural dimensions of communication, including appeals to collective identities, emotional solidarities, and the promotion of moral exemplars (Jaspers, 2010; Kavada, 2013).

Accordingly, we combine the study of external communication of movements with an analysis of the dynamics driving internal processes (Treré, 2012), differentiating internal (or inward) and external (or outward) functions of communication (Cammaerts, 2007). Inward roles, or internal communication, refer to the structuring of organization, the management of internal debates and decision-making; outward roles, or external communication, relate to mobilization, recruitment, and the creation of independent channels of communication and alternative media spaces (Cammaerts, 2015). Previous literature suggests that movements face distinct sets of strategic challenges depending on whether their communication is inward-oriented, i.e. primarily aimed at internal mobilization and identity building (or inbound self-representation, see: Uldam and Askanius, 2011),

\footnotetext{
${ }^{2}$ With the 'cultural turn' of the social sciences, culture has come to represent a growing domain of research in the field of social movements, including studies on framing and collective identities (for an extensive overview of the many existent cultural approaches and their shortcomings, see: Ullrich, Daphi and Baumgarten, 2014).
} 
or outward-oriented, i.e. primarily aimed at external mobilization and attention (McAdam, 2005). By differentiating between inward- and outward-oriented media practices, we appraise means of communication as means of production, in that the media not only enable actors to mobilize cultural resources, but also act as arenas of political and identity contention (e.g. Kaun, 2016). Put differently, far-right media practices are not only constituted by existing knowledge embedded in social movements, but are also in themselves constitutive of the collective identities of extreme right groups (Atton, 2006).

In the following sections, we elaborate on our case selection and data, before moving on to discussing the media practices and political culture of extreme right social movements in Italy and France. In line with previous studies on right-wing resistance performance (Atkinson and Berg, 2016), our analysis shows how extreme right groups have worked to create their own media networks through alternative web services and platforms, including the creation of portals, web TV, radio and news outlets. On the one hand, we highlight the relevance of extreme right political cultures to explain the practices by which right-wing social movements appropriate and engage with the media, and to make sense of how they use alternative networks to foster cultural division and pursue their metapolitical projects. On the other, we illustrate that media practices can reshape political cultures, by changing the way in which activists make sense of their political engagement. In the conclusions, we elaborate on how the findings of this research contribute to ongoing discussions on the role of the media in collective action, and provide some theoretical and methodological insights to further explore farright activism in Europe.

\section{Case study and methods}

The study looks at two extreme-right organizations sharing similar ideological and organizational traits: Les Identitaires (LI) in France and CasaPound Italia (CPI) in Italy. Both LI and CPI represent emergent organizations rather than established political parties, and originate in the social movement arena. This is most appropriate to the study of media practices, because unlike established actors which can count on the mass media at all times - non-established ones have to demonstrate that they are worth some attention, by means of targeted media practices (Bouron and Froio, 2018). Furthermore, the two groups share a background in the Identitarian movement and the New Right, ${ }^{3}$ which inspires their criticism of modern economic thinking, as well as a propensity towards ecology, communitarianism, anti-imperialism and Europeanism (Bouron, 2015; Froio and Castelli Gattinara, 2015). LI and CPI are thus comparable in terms of both ideology and organization. ${ }^{4}$

CPI first appeared in 2003, when a building in Rome was squatted by a group of disenfranchised neofascist militants (Albanese et al., 2014). The group initially referred to the youth section of Fiamma Tricolore, ${ }^{5}$ but tensions soon emerged concerning party leadership accountability, leading to a

\footnotetext{
${ }^{3}$ The Nouvelle Droite (New Right) is a prominent political stream of Europe's right-wing thought. Originally developed in France in the 1960s, it opposes liberal democracy, multiculturalism and the mixing of different cultures (Bar-On 2012).

${ }^{4}$ As for the cross-national comparison, Italy and France are generally considered to belong to similar clusters of media systems (Hallin and Mancini, 2004; Brüggemann et al., 2014, p. 1057).

${ }^{5}$ Movimento Sociale - Fiamma Tricolore is a neo-fascist party started by members of the pre-existing Italian Social Movement who refused to accept the moderate turn imposed on the party in the early 1990s (see: Ignazi, 2003).
} 
splinter and the establishment of CPI as an autonomous non-profit association. Openly rejecting 'leftwing' and 'right-wing' labels, CPI claimed its difference from traditional parties and rooted itself in the tradition of Italian Fascism (Albanese et al., 2014). Starting from 2013, CPI regularly took part in elections with its own electoral lists, scoring rather poor results at the national level (0.14 per cent), but securing the election of its officials in some local councils in Italy. LI is a nativist movement founded in 2003 by a group of sympathizers of the Front National ${ }^{6}$ and the outlawed group Unite Radicale, ${ }^{7}$ which evolved into a main network of right-wing football hooligans, disenfranchised youth organizations, sport associations and 'identitarian rock' bands (Bouron, 2015). Rallying for French and European 'patriots', and challenging Islam and globalization, the group has a youth section (Génération Identitaire) with spin-off organizations in Italy, Germany and Austria. Like CPI, LI addresses primarily young generations, and its self-styled activism privileges community-building practices (concerts, sports, excursions), as well as contentious actions aimed at setting the media agenda, over office-seeking activities and electoral participation.

The empirical analysis is based on semi-structured interviews and ethnographic sessions conducted by the authors at events organized by CPI and LI between 2012 and 2014. So far, the study of the far right has been predominantly preoccupied with 'externalist', rather than 'internalist', explanations (Goodwin, 2006), as only very rarely could researchers access insider information about the workings of extremist organizations from activists themselves (Blee, 2002; Kimmel, 2007). Moreover, the study of these movements from outside makes it difficult to understand what attracts activists, and how their political culture has been adapted to forms of contemporary communication (Kavada, 2013). The ethnographic approach is thus coherent with our research focus on culture, discourse and practice, as it relies on an understanding of communication that goes beyond the simple transmission of discursive elements to the media, which could be appraised by looking at what they write and what is written about them (Blee, 2007).

However, the study of movement groups that are illegal, inaccessible, or ideologically unappealing poses ethical and practical challenges of its own, especially concerning the research role to adopt and the type of relation to establish with the research subject (Blee, 2007). But this decision is never taken by the researcher alone, since ethnographic research is interactional (Esseveld and Eyerman, 1992, p. 228-229). As a result, it was only possible to access to the field in Italy after negotiation with CPI leaders, so that all activists were informed of our position as researchers, whereas the same was not possible in France, as group leaders were unwilling to grant access to external observers. ${ }^{8}$ Considering the focus of this study on communication and media practices (rather than more sensitive emotional and ideological aspects), we are however confident that the different research roles do not carry any substantial bias for the analyses of the present study. Previous literature also dealt with ethical issues stemming from these research choices (Esseveld and Eyerman, 1992). In this respect, the authors participated exclusively in legal events, such as conferences, celebrations, concerts, summer camps and authorized demonstrations, in which they could encounter sympathizers and militants without being 'monitored' by local cadres and leaders.

\footnotetext{
${ }^{6}$ Founded by Jean-Marie Le Pen in 1972, and led by his daughter Marine since 2011, the National Front is one of the most influential populist radical right parties in Western Europe.

${ }^{7}$ Unité Radicale was a French national-revolutionary group founded in 1998 and dissolved in 2002 after the failed assassination of President Jacques Chirac by one of its members.

${ }^{8}$ For further details, see: Albanese et al., 2014; Bouron, 2015.
} 
Overall, the observation was based on several sessions and lasted for about one year. The interaction with militants allowed researchers to reconstruct the processes by which collective emotions are built, to investigate their expression in the internal codes of the group, and to assess the extent to which external discourses are internalized by militants and supporters. In order to make analytic claims, we integrated this with evidence from qualitative content analysis on the material produced by the group for propaganda (collected during the ethnographic sessions), and from in-depth interviews with militants and officials, using life histories as a hermeneutical mode to appraise ideology, militancy and interaction with the mass media (Linden and Klandermans, 2007).

\section{Inward-oriented and outward-oriented media practices of the extreme right}

\section{The internal dimension: inward-oriented media practices}

Media practices stood out primarily for their inward-oriented function, for the communication with group members, and for the diffusion of messages in the extreme right milieu. Furthermore, previous studies looking at the interplay between activism, representation and practices of resistance argued that mediation can also act to reinforce the sense of political identity and commitment among group members (Uldam and Askanius, 2011). Similarly, through ethnographic observation, we could see how these practices represent more than a mere communicative tool, and how they actively contribute to binding together core-activists and sustaining the internal hierarchies of CPI and LI. More specifically, inward-oriented media practices serve three primary functions, related to the structure of the organizations, the profile of group members, and the diffusion of their messages among supporters (Pirro and Castelli Gattinara, 2018).

Concerning organization, there is a considerable symmetry between CPI's internal structure and its media apparatus. The group can count not only on official social media profiles (Facebook 200,000 likes; Twitter 18,000 followers), and on a website summarizing its basic values, activities and proposals, but also on dedicated pages for each territorial branch, and individual pages for national leaders and candidates. Despite this fragmentation, these online platforms are very coherent in aesthetic choices and in the diffusion of messages, facilitating the construction of shared meanings and goals among militants and sympathizers. In particular, CPI emphasizes its organic understanding of national identity, state sovereignty and legitimacy, conceived as natural expressions of the Italian nation: 'The Italian nation needs to become once again a national organism with powerful and longlasting life, aims and means of action, which are well above those of its single or grouped individuals' (CPI, 2017b).

This fragmentation is, however, reconciled in the group's main portal, which reproduces the network of CPI's galaxy, illustrating the symmetry between offline structures and their reproduction online. ${ }^{9}$ If each political campaign is associated with a specific organization having exclusive policy responsibilities, online each campaign can count on a dedicated website reporting information on the issue at stake, activities, coverage and events. Each thematic group is thus organized as a sub-entity

\footnotetext{
${ }^{9} \mathrm{We}$ are not suggesting that the structure of the web portal shapes the group's offline organization. On the contrary, we believe that the influence between organization and media technologies is most likely mutual, and that both owe to the group's worldview and political culture.
} 
of the main organization, but has a dedicated website for its specific activities, such as social voluntary work (e.g. environmental protection), leisure activities (sports, excursions), and international cooperation (solidarity). First introduced by CPI, this model seems to have inspired other groups of the Italian extreme right. ${ }^{10}$ To substantiate internal communication within this network, CPI promotes two main independent media platforms: a web TV (TortugaTV), and a web radio (Radio Bandiera Nera), which provide information on movement activities, with live reports and podcasts from events, as well as reports, music events and entertainment. Discussions with militants confirmed that these media platforms act as both a public archive of CPI, and as an instrument of cultural socialization for group members. In terms of identity building, a crucial role is played by CPI's music band ZetaZeroAlfa and the websites merchandising highly recognizable cultural products (t-shirts, hoodies, CD albums, books).

What brings together these practices is precisely the need of the movement to become recognizable. The graphic design and format of all websites and platforms are intended to provide a sense of ideological purity and belonging, not only through the selection of symbols, but also through the homogeneity of colours and fonts. The online apparatus is structured along very homogeneous lines, format and colours, creating a continuity between the main portal and the pages of its peripheral organizations, and increasing the distinctiveness of the network. At the same time, these choices closely correspond to those observed also in CPI'S offline communication and activities. The coherence of CPI's network is ensured by online activists and 'web-supporters'. Web supporters are 'CPI's online task force' and are as important as other members and activists, because CPI must "preserve a space of freedom in the internet, just like we do in the streets, in schools and in universities" (CPI, 2017a). They are appointed among sympathizers who do not have the possibility of becoming active militants, and are thus charged with specific online activities. In this respect, CPI's media practices also produce innovative and more flexible forms of participation beyond traditional party membership.

As for LI, inward-oriented communication practices have to be understood as part of a broader cultural and political project. The group's overarching idea is in fact 'meta-political' in nature, and it expects that the limited community of identitarian sympathizers will grow progressively by reaching out to new audiences through cultural, rather than strictly political, projects. According to one of the founders of the group, the rationale is 'to attract people who would hardly ever join traditional forms of political activism and militancy. The goal is to act on their perception of the world and of the society they live in, making their opinions progressively favourable to our struggles, to our project, and to our political movement' (Vardon, 2011, p. 175). In fact, media practices result from a strict apportioning of labour between the two components of the organization: Bloc Identitaire and its youth section Génération Identitaire. If the youth section focuses more on the pars destruens, i.e. the critique of the news system, the Bloc engages primarily in the pars construens, i.e. the promotion of an alternative media space and knowledge (Cardon and Granjon, 2013). Both activities, however, stem from the same ideological conviction that a single, hegemonic ideology drives mainstream politics and the financial system, marginalizing all forms of critique.

In response, the Bloc promotes Novopress, a news agency aimed at building counter-hegemonic narratives against mainstream media. With the goal of creating a system of 're-information', the

\footnotetext{
${ }^{10}$ The websites of the neo-fascist Forza Nuova and Lealtà-Azione now follow this design.
} 
platform offers three types of information. First, it offers visitors a general coverage of public issues of interest to the movement by reporting articles published on mainstream right-wing outlets, but that frame these problems in a way that is compatible with the group's values (e.g. critique of immigration and Islam). Second, it produces its own news objects, using a seemingly objective journalistic style and language, but taking content from media sources that are ideologically contiguous to LI, including extreme right websites such as Présent, Polemia, and Boulevard Voltaire. Third, it provides information on the intellectual field of the French extreme right, with articles and commentaries on the work of public figures such as Eric Zemmour and Renaud Camus. Similarly, territorial sections of Génération Identitaire set up websites to inform sympathizers about activities and events, often retrieving text from the local press and the internet.

From 2012, however, Génération Identitaire has taken on its own identity and autonomy, with the goal of transforming into a pan-European movement. As in the case of CPI, the construction of such an online network required a coherent standard of online activism, based on a highly recognizable identitarian brand, which could act as a bridge between different ideological, cultural and merchandising products and web platforms. Indeed, militants and leaders of Génération Identitaire engaged in a veritable project of graphic homogenization of the group's web resources. Throughout this transformation, as we were able to observe, the social media became a crucial tool to bind the militant community and to circulate material and information on protest actions and the militant lifestyle. Counting on tech-savvy personnel, the Identitarians shoot videos of their political actions. The aim is to embed the public in the protest. Accordingly, they use subjective camera devices to offer a full 'immersion' in identitarian action, and emulate the techniques of the videogame and music industry to present the playful dimension of activism (Fourquet-Courbet and Courbet, 2015).

Online platforms thus offer a first space of identification with the group, especially in terms of music events, humanitarian and solidarity activities, as well as other forms of cultural engagement. This is then consolidated offline, during summer camps where activists are introduced to the Identitarian militant sphere, and to its communication and ideological style. In this respect, the ethnographic observation revealed the emotional dimension of militancy, which is activated through offline practices aimed at increasing members' feeling of belonging (Ezekiel, 2002), and then sustained through media practices, photos and videos aimed at reviving the activist community and identity online (Simi et al., 2017). Furthermore, these media products act as propaganda devices and have sometimes managed to reach out beyond the milieu of the French extreme right. Many of the militants that we met were indeed former members of the Front National, who had joined Génération Identitaire primarily because of the sociability they found when participating in communitarian life and collective action. Furthermore, the groups' online following increased dramatically in a few years: by the end of 2017 Génération Identitaire had more than 125,000 followers on Twitter, greatly outnumbering the youth section of Front National $(90,000)$ and the French Socialist Party $(30,000)$.

Overall, our study shows that the crucial underlying element of inward-oriented activism by LI and CPI is the construction of a clearly recognizable brand identity, associated with an alternative culture and community (Atkinson and Berg, 2016). This is achieved by means of an explicit effort to reproduce symbolic, graphic and ideological consistency across various communication platforms, information sites and online media. Both groups display a considerable heterogeneity in the communication tools that they promote, but they ensure that these diversified channels provide a recognizable profile to the movement and symbolically represent its core values and lifestyles. In so doing, they provide continuity between the online apparatus and the offline militant base: 
communication platforms are thus a primary source of information about, and identification with, the collective life of the group, its cultural activities and its meta-political projects. Hence, rather than being solely an instrument of internal propaganda and control, inward-oriented media practices serve the purpose of building the collective identity of the groups, binding militants within a common culture and ensuring their coherent representation towards the outside world.

\section{The external dimension: outward-oriented media practices}

The second dimension of extreme right activism concerns practices addressing the 'external' world. At the most general level, outward-oriented media practices relate to the need of these actors to get the attention of mainstream media. They aim at mobilizing beyond established constituencies, and at overcoming problems of social control, repression and counter-mobilization. In this framework, the media are conceived as a means of shaping public policy and state action, and/or to set the terms of public debates and agendas. In this respect, our ethnographic work confirms that extreme right militants are well aware that their visibility depends on the capacity to offer the media a product that is at the same time personalized, spectacularized and creating controversy and debate (see, e.g. Altheide, 2004; Esser, 2013). We shall therefore appraise media practices primarily in terms of personalization, dramatization and simplification of communication. ${ }^{11}$

In CPI, personalization takes place primarily through the centrality of the leader, who creates or displaces social movement practices and accompanies virtually all actions that can be associated with the group, in line with the leadership principle that guides far-right politics. In addition, personalization takes place through the systematic exhibition of symbols that can be immediately associated with the group. On the one hand, CPI pays particular attention to the promotion of its events on its online platforms, so that journalists often find all the information, photos and material they need directly from the sources of the relevant group, thus exerting control over its own imagery and narratives. On the other hand, demonstrations and public events are organized and planned with extreme caution, so that the group can anticipate the 'iconographic' result of its interventions.

To begin with, therefore, outward-oriented media practices by CPI have to do with the group's stated objective of legitimizing alternative extreme-right thinking. In this respect, CPI interacts with the media primarily with the goal of generating controversy and attracting attention, by means of careful symbolic and discursive choices. In terms of political symbols, CPI takes a distance from the traditional symbolism of the Italian extreme right, and offers a hybrid media product associating pop and left-wing icons, with extreme right codes. The goal is not only to empty established symbols (such as Che Guevara, Chavez and Marx) of their meaning, but also to present an innovative, or at least unusual, narrative, thus responding to the commercial needs of the mass media. Discursively, instead, CPI has tried to reverse the national narrative on fascism and anti-fascism, calling on a national reconciliation 'beyond anti-fascism'. Mobilizing strategically on liberal democratic values, and using pseudo-progressive tropes, CPI accuses the political mainstream of marginalizing, and repressing, the free speech of neo-Fascists on issues as varied as the environment, the economy, culture and so on (Castelli Gattinara, 2017).

\footnotetext{
${ }^{11}$ In this respect, scholars of communication use the concept of 'media logic' to indicate the set of codes and rules that define the production of media content (Altheide, 2004).
} 
In addition, media practices emerged from our observation in the field, as we were directly confronted with various forms of iconographic staging of public events. To maximize the visual impact of CPI's demonstrations, participants form ranks of seven/eight persons, and then march in orderly lines separated from one another by a maximum of two metres. A security service is in charge of ensuring that all participants stand in position, walk simultaneously, and sing the chants and slogans when asked to. The organizers make sure that colourful smoke bombs (reproducing the colours of the Italian flag) and other showcase actions take place simultaneously to increase their emotional impact. Activists can display no symbol other than that of CPI (including its youth section) and the Italian flag during the demonstration. The flags are distributed at the beginning of the rally to selected groups of participants, to provide an image of discipline and homogeneity. Ideologically, these practices clearly reflect the idea of order and unity that the group endorses and seeks to display towards the outside world. Strategically, they help the group to exert control over its own image when it interacts with the mass media during public events. Put differently, choices in the staging of public events stem from the need to increase CPI's public appeal via targeted visual strategies, but also from the need to keep more violent and extremist elements at bay by implementing some form of control during public events. In general, the combination of these various dimensions defined the group's political paradigm as a social movement until today, and provided the group with considerable attention in the Italian media system, enabling it to extend its visibility well beyond the extreme right milieu.

As regards LI, outward-oriented media practices owe much to the personal and professional knowledge of its founders, Fabrice Robert and Philippe Vardon, who hold university degrees in political science and have a background as communication consultants in the private sector. The movement's multimedia content, as well as its graphic and symbolic choices of communication, configure an elaborate technique oriented at maximizing the impact of mobilization on news coverage. To achieve this goal, LI deploys a strategy of symbolic appropriation comparable to that of CPI: rather than rejecting the culture produced by political opponents and the commercial media, the group tries to appropriate and reinterpret these figures, adjusting them to their own interpretations and narratives. This mechanism has been applied to mass cultural products, such as the movies Fight Club and 300 which have become crucial references for the group's collective identity, as well as to the symbols of left-progressive movements, such as Greenpeace and the housing movements, which are used as inspirational examples for extreme right activism.

Furthermore, LI activists are aware that in order to gain legitimacy in mainstream media, they must produce news material that displays qualities that are at least comparable to those of professional news content, and that does not seem amateur. During our ethnographic observation, we witnessed directly that militants are purposely trained to achieve convincing standards of output production. When a sympathizer is allowed to participate in LI's summer camps, thus signaling the will to become an active member, the group organizes targeted training session to increase his/her communication skills. This includes classes on how to write press releases, how to develop websites and online platforms, how to draft banners and stencils, as well as public speaking courses. Militants thus receive specific training to gain the skills necessary to interact with the media. Next to the obvious advantages in terms of the group's visibility, the militant training in communication skills also ensures the centralization and homogenization of all communication produced by identitarian activists. In this respect, it represents a media practice responding to ideological as well as practical incentives. It not only relates to values of hierarchy and centralization embedded in extreme right political culture, but 
it also relates to logics of efficiency, so that the radical, transgressive and even violent aspects of LI's activism are transformed into aesthetic objects, possibly increasing their spectacular and news value.

The result is that the communication style of LI rests more on the logics of advertising and entertainment than on those that characterize traditional extreme right politics. They stage and film their protest action, and then diffuse the self-produced images via social networks, independent news agencies and the local media.

The group's expressive and spectacular actions have thus the explicit goal of imposing certain issues, or types of debate in the political sphere. LI militants and officials are explicit in stating that their vigilante activism against insecurity, as well as their anti-Muslim initiatives, have the primary objective of building the political agenda, and imposing a certain vocabulary on public debates. The success of these practices is thus not measured in terms of policy-making, nor in terms of any material, direct intervention over a problem. Rather, it depends on the change they produce on public discourse, on their capacity to grant LI some space in the media agenda, and on the extent to which they force other political actors to respond.

Comparatively, the outward-oriented communication practices of CPI and LI display substantial traits of similarity. Above all, both actors have tended to professionalize their practices and bypass the role of journalists as primary gatekeepers of news value. This is based on the awareness that visibility crucially depends on the capacity to offer the media a product that they can easily and successfully sell to a generalized public. If their actions are not able to produce this type of story, the only way to get visibility is through street violence and open confrontation with opponents, which is risky for organizations located at the far-right of the political spectrum. LI and CPI thus demonstrated a considerable knowledge of the logics defining the interaction between mass media and social movements, developing a form of storytelling based on dramatization of narratives, visual staging of protest, and the construction of controversy by means of symbolic innovation and discursive hybridisation. While in Italy this form of activism has developed to represent a corollary of other more traditional - forms of extreme right-wing engagement, in the case of France the media dimension has come to dominate extreme right street politics, with the result that outward-oriented communication and agenda setting have become the foremost objective of political action, if not the only one.

\section{Conclusions}

We began this study with a consideration of the ambiguous relationship between the far right and the media. Following the literature of social movements, we set out to provide a first empirical assessment of the media politics of extreme right organizations, examining the interplay between media practices and extremist political culture in Italy and France. Specifically, we focused on the media as the discursive and technological environment within which movement actors of the extreme right articulate their political demands, renegotiate their collective identities, and ultimately try to further their causes (McCaughey and Ayers, 2013). In so doing, we sought to reveal the system of meaning lying behind the media practices of extreme right actors, in terms of beliefs and values, as well as practices and narrative construction.

The mixed-methods analysis conducted in this study confirmed the appropriateness of using media practices as a heuristic device to interpret the interplay between communicative choices and extreme 
right political culture. Indeed, extreme right media practices stand out for their metapolitical nature, configuring a veritable cultural project. They articulate a variety of activities, performances and events aimed at not only consolidating right-wing ideas and values within the groups' own milieu of sympathizers and potential supporters, but also at spreading an alternative world-view in mainstream society, influencing politics and politicians through culture rather than political action. Right-wing actors have created their alternative media spaces, which are used to pursue a cultural and political agenda of resistance against mainstream society, as well as to reify and reproduce the sense of collective belonging of militants and sympathizers. Media practices thus configure not only the means of communicating extreme right ideals, but also of producing new meanings and collective identities. In this respect, the media represent an important device to express far-right understandings of social and political change, and a crucial field in which these organizations construct and manifest their own image, narrative and identity. We have illustrated how far-right values concerning order, hierarchy and homogeneity permeate the graphic, visual and discursive choices of CPI and LI's communication. At the same time, we have provided evidence that the whole process of extreme-right news production is imbued with notions of discipline, and that it is regulated through a strict chain of command stemming from both ideological incentives and strategic constraints for the two organizations.

The analytical distinction between the media as a means of internal mobilization and formation, and its function as an object of political action aimed at external mobilization and attention (McAdam, 2005), allowed us to demonstrate how the political culture of extremist right-wing groups differently affects inward-oriented identity-building activities, and outward-oriented agenda setting action. If LI and CPI display an unexpected knowledge of the logics driving news production, which incentivizes a communication style based on dramatizing and symbolic hybridization, internal media politics focuses primarily on reinforcing ideological consistency and subcultural identification, constructing a brand identity that ensures internal cohesion and external distinctiveness. Hence, inward-oriented activism stands out for its function in structuring collective identities and ideological coherence, whereas outward-oriented communication connects more closely to extreme right general understandings of political engagement. Both dimensions, however, testify to the crucial importance extremist right wing organizations attribute to political communication and media practices. Internally, they have engaged considerably in differentiating the channels of communication between the organization, its militant base and the broader audience of potential supporters and sympathizers. Externally, they have improved the quality and effectiveness of their communication tools, by investing in the professional training of activists and militants, and by reformulating their storytelling and strategy of contention in line with the visual and discursive preferences of the commercial media.

While we acknowledge that our study only offers an explorative step towards understanding the interaction between the media and far-right politics, we believe that the approach followed here provides valuable information on the mechanisms behind contemporary right-wing extremism. First, it broadens the scope of existing studies on alternative media and contemporary activism (Atkinson and Berg, 2016; Atton, 2006), offering primary information on the rationale for the construction of alternative media networks by extreme right organizations and on the political and cultural role that independent far-right web services and media platforms play in contemporary politics. Second, it provides original empirical insights on the media activism of extreme right organizations, and on how they try to shape public agendas. And third, it offers a preliminary explanation of how protest movements such as CasaPound Italia and Les Identitaires, have consolidated their profile and become widely recognizable in the Italian and French public spheres. Only future research will be able to 
judge whether and to what extent similar actors will succeed in shaping public discourse in the long term, especially on crucial issues linked to migration and cultural diversity. In this respect, the identification of the metapolitical dimension of right-wing media activism should not obfuscate the ultimate aim of extreme right movements which remains the radical exclusionist upheaval of European politics, society and culture.

\section{References}

Akkerman, T. (2011) 'Friend or foe? Right-wing populism and the popular press in Britain and the Netherlands’, Journalism, 12(8), pp. 931-945.

Albanese, M., Bulli, G., Castelli Gattinara, P. and Froio, C. (2014) Fascisti Di Un Altro Millennio? Crisi e Partecipazione in CasaPound Italia. Roma/Acireale: Bonanno Editore.

Altheide, D.L. (2004) 'Media Logic and Political Communication', Political Communication 21(3), pp. 293-96.

Arzheimer, K. and Carter, E. (2006) 'Political opportunity structures and right-wing extremist party success', European Journal of Political Research, 45(3), pp. 419-443. doi: 10.1111/j.14756765.2006.00304.x.

Atkinson, J. and Berg, S. (2016) 'Right Wing Activism: The Next Challenge for Alternative Media Scholarship', in Hug, T and Sützl, W (Eds.), Activist Media and Biopolitics: Critical Media Interventions in the Age of Biopower. Innsbruck: Innsbruck university press, pp. 117-33.

Atkinson and Berg, 2016Atton, C. (2006) 'Far-right media on the internet: culture, discourse and power', New Media \& Society, 8(4), pp. 573-587. doi: 10.1177/1461444806065653.

Bar-On, T. (2012) 'The French New Right's Quest for Alternative Modernity', Fascism, 1(1), pp. 18-52. doi: 10.1163/221162512X631198.

Blee, K.M. (2002). Inside organised racism: women in the hate movement. Berkeley: University of California Press.

Blee, K.M. (2007) 'Ethnographies of the Far Right', Journal of Contemporary Ethnography, 36(2), pp. 119-128.

Boomgaarden, H. G. and Vliegenthart, R. (2007) 'Explaining the rise of anti-immigrant parties: The role of news media content', Electoral Studies, 26(2), pp. 404-417. doi: 10.1016/j.electstud.2006.10.018.

Bouron, S. (2015) 'Un militantisme à deux faces', Agone, 54, pp. 45-72.

Bouron, S. and Froio, C. (2018) 'Entrer en politique par la bande médiatique? Construction et circulation des cadrages médiatiques du Bloc identitaire et de Casapound Italia', Questions de Communication, 33(1), 209-229.

Brüggemann, M. et al. (2014) 'Hallin and Mancini Revisited: Four Empirical Types of Western Media Systems', Journal of Communication, 64(6), pp. 1037-1065. doi: 10.1111/jcom.12127. 
Caiani, M. and Parenti, L. (2009). 'The Dark Side of the Web: Italian Right-Wing Extremist Groups and the Internet', South European Society and Politics, 14(3), s. 273-294.

Cammaerts, B. (2007) 'Media and communication strategies of glocalized activists: beyond mediacentric thinking', in Cammaerts, B. and Carpentier, N. (Eds.), Reclaiming the media: communication rights and democratic media roles. Bristol: Intellect Books, pp. 265-288.

Cammaerts, B. (2015) 'Social Media and Activism', in Mansell, R. and Hwa, P., The international encyclopedia of digital communication and society. Oxford: Wiley-Blackwell, pp. 1027-1034.

Cardon, D. and Granjon, F. (2013) Médiactivistes. Paris: Presses de Sciences Po.

Caren, N. Jowers, K. and Gaby, S. (2012). 'A social movement online community: Stormfront and the White nationalist movement', Social Movements Conflict and Change, 33, pp. 163-193.

Castelli Gattinara, P. (2017) 'Framing Exclusion in the Public Sphere: Far-Right Mobilisation and the Debate on Charlie Hebdo in Italy', South European Society and Politics, 22(3), pp. 1-20.

Castelli Gattinara, P. and Froio, C. (2018). 'Getting 'right' into the news: mobilization and media coverage of non-established extreme right actors in Italy and France', Comparative European Politics, Online First. DOI: 10.1057/s41295-018-0123-4.

Castelli Gattinara, P. and Pirro, A. L. P. (2019) 'Introduction: The Far Right as Social Movement', in European Societies, issue 2, 2019. Online First, https://doi.org/10.1080/14616696.2018.1494301.

Couldry, N. (2004) 'Theorising media as practice', Social Semiotics, 14(2), pp. 115-132.

CPI (2017a) 'Aperto il tesseramento 2017'. Available at: http://www.casapounditalia.org/2013/03/new-aperto-il-tesseramento-2013-sia-per.html (Accessed: 29 September 2017).

CPI (2017b) 'Chi Siamo'. Available at: https://www.docdroid.net/iEyLzrj/brochurechisiamo.pdf (Accessed: 29 September 2017).

Ellinas, A. (2010) The media and the far right in western Europe: playing the nationalist card. Cambridge: Cambridge University Press.

Esser, F. (2013) 'Mediatization as a challenge: media logic versus political logic', in Kriesi, H. et al., Democracy in the age of globalization and mediatization. Basingstoke: Palgrave, pp. 155-176.

Esseveld, J. and Eyerman, R. (1992) 'Which Side Are You On? Reflections on Methodological Issues in the Study of "Distasteful" Social Movements', in Diani, M. and Eyerman, R., Studying Collective Action. London: Sage, pp. 217-237.

Ezekiel R. S. (2002), 'An Ethnographer Looks at Neo-Nazi and Klan Groups. The Racist Mind Revisited', American Behavioral Scientist, vol. 46, 1: pp. 51-71.

Fourquet-Courbet, M.-P. and Courbet, D. (2015) 'Les serious games, dispositifs de communication persuasive, Serious games : persuasive communication devices', Réseaux, 6(194), pp. 199-228.

Froio, C. (2017) 'Nous et les Autres. L'altérité sur les sites web des extremes droites en France', Reseaux, 202(2), pp. 39-78.

Froio, C. and Castelli Gattinara, P. (2015) 'Neo-fascist mobilization in contemporary Italy. Ideology and repertoire of action of CasaPound Italia.', Journal for Deradicalization, 0(2), pp. 86-118. 
Golder, M. (2016) 'Far Right Parties in Europe', Annual Review of Political Science, 19(1), pp. 477497. doi: 10.1146/annurev-polisci-042814-012441.

Goodwin, M. J. (2006) 'The Rise and Faults of the Internalist Perspective in Extreme Right Studies', Representation, 42(4), pp. 347-364. doi: 10.1080/00344890600951924.

Hallin, D. C. and Mancini, P. (2004) Comparing Media Systems: Three Models of Media and Politics. Cambridge University Press.

Ignazi, P. (2003) Extreme Right Parties in Western Europe. Oxford: Oxford University Press.

Jasper, J. M. (2010) 'Cultural Approaches in the Sociology of Social Movements', in Klandermans, B. and Roggeband, C., Handbook of Social Movements Across Disciplines. Boston: Springer, pp. 59109.

Kaun, A. (2016) Crisis and Critique: A Brief History of Media Participation in Times of Crisis. Zed Books Ltd.

Kavada, A. (2013) 'Internet cultures and protest movements: the cultural links between strategy, organizing and online communication', in Cammaerts, B., McCurdy, P., and Mattoni, A. (Eds) Mediation and Protest Movement. London, Intellect, pp. 75-94.

Kimmel, M. (2007) 'Racism as adolescent male rite de passage. Ex-Nazis in Scandinavia', Journal of contemporary ethnography, 36(2), s. 202-218.

Kubitschko, S. (2017) 'Acting on media technologies and infrastructures: expanding the media as practice approach', Media Culture and Society, 0(0), pp.1-7. Doi/10.1177/0163443717706068

Linden, A. and Klandermans, B. (2007) 'Revolutionaries, Wanderers, Converts, and Compliants: Life Histories of Extreme Right Activists', Journal of Contemporary Ethnography, 36(2), pp. 184-201.

Mattoni, A. (2012) Media Practices and Protest Politics: How Precarious Workers Mobilise. Aldershot: Ashgate Publishing.

Mattoni, A. (2017) 'A situated understanding of digital technologies in social movements. Media ecology and media practice approaches’, Social Movement Studies, 16:4, 494-505

Mazzoleni, G. (2008) 'Populism and the Media', in Albertazzi, D. and McDonnell, D. (Eds.), TwentyFirst Century Populism. Palgrave Macmillan UK, pp. 49-64.

McAdam, D. (2005) 'Movement Strategy and Dramaturgical Framing in Democratic States: The Case of the Civil Rights Movement', in Chambers, S. and Costain, A., Deliberation, Democracy and the Media. Lenham: Rowman \& Littlefield, pp. 117-35.

McCaughey, M. and Ayers, M. D. (2013) Cyberactivism: Online Activism in Theory and Practice. Routledge.

Mudde, C. (2007) Populist radical right parties in Europe. Cambridge, UK; New York: Cambridge University Press.

Pirro, A.L.P. and Castelli Gattinara, P. (2018) 'Between Movement and Party: Enquiry Into the Organisation and Strategies of the Far Right', Mobilization, International Quarterly, 23(3) : 367-383) 
Sheets, P., Bos, L. and Boomgaarden, H. G. (2015) 'Media Cues and Citizen Support for Right-Wing Populist Parties', International Journal of Public Opinion Research. 28(3), pp. 307-330.

Simi P., Blee K., De Michele M., Windischd S., 'Addicted to Hate: Identity Residual among Former White Supremacists', American Sociological Review, 2017, Vol. 82(6) 1167-1187.

Uldam, J. and Askanius, T. (2011) 'Calling for confrontational action in online social media: video activism as auto-communication', in Cammaerts, B., McCurdy, P., and Mattoni, A. (Eds) Mediation and Protest Movements. Bristol: Intellect, pp. 159-178.

Treré, E. (2012) 'Social Movements as Information Ecologies: Exploring the Coevolution of Multiple Internet Technologies for Activism', International Journal of Communication, 6, pp. 2359-2377.

Ullrich, P., Daphi, P. and Baumgarten, B. (2014) 'Protest and Culture: Concepts and Approaches in Social Movement Research - An Introduction', in Baumgarten, B., Daphi, P. and Ullrich, P. (Eds.) Conceptualizing Culture in Social Movement Research. Basingstoke: Palgrave MacMillan, pp.1-22.

Vardon, P. (2011), Éléments pour une contre-culture identitaire. Nice, IDées. 